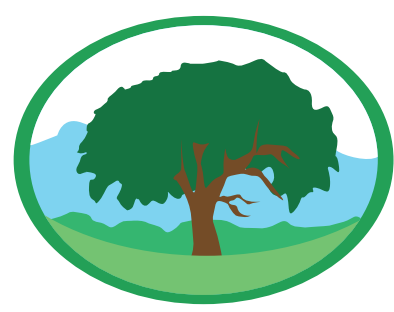

\title{
EFICIÊNCIA DE COAGULANTES NA REMOC̣ÃO DE MANGANÊS
}

LOPES, B.V. ${ }^{1}$; HEYLMANN, K.K.A. ${ }^{1}$; VIEGAS, D.P. ${ }^{2}$; SILVA, R.F. ${ }^{3}$; QUADRO, M.S. ${ }^{1,4}$; ANDREAZZA, R. ${ }^{1,4}$.

${ }^{1}$ Engenharia Sanitária e Ambiental - UFPel

${ }^{2}$ Embrapa Clima temperado

${ }^{3}$ Programa de Pós Graduação em Agronomia: Agricultura e Ambiente - UFSM

4Programa de Pós Graduação em Ciências Ambientais - UFPel

Palavras-chave: Tratamento de água, poluição, saneamento.

\section{Resumo}

O Mn, se consumido em altas concentrações pela população, pode acarretar problemas de saúde, principalmente pela ingestão de água potável. Desta forma, o objetivo deste estudo foi avaliar a eficiência da remoção dos íons de Manganês na água bruta com a adição de diferentes coagulantes e concentrações de íons $\mathrm{Mn}$ na água bruta. Foram utilizadas diferentes concentrações de $\mathrm{Mn}$, de 2 à $6 \mathrm{mg} \mathrm{L}^{-1}$, e avaliado três diferentes coagulantes: Sulfato de Alumínio, Tanino e Policloreto de Alumínio, para o tratamento de água. Os resultados demonstraram que os coagulantes Tanino e Policloreto de Alumínio apresentaram os melhores potenciais de remoção do $\mathrm{Mn}$, sendo a maior eficiência apresentada para o coagulante Tanino na água bruta sem adição de $\mathrm{Mn}$, e para a água bruta com adição de $2 \mathrm{mg} \mathrm{L}^{-1}$ de $\mathrm{Mn}$. 0 coagulante Policloreto de Alumínio obteve a maior eficiência apenas para a água bruta com adição de $6 \mathrm{mg} \mathrm{L}^{-1}$ de Mn. O Sulfato de Alumínio apresentou os piores índices de remoção. Em situação de maior concentração de íons de $M n$ na água bruta da região, o coagulante mais eficiente para a remoção do Mn é o Policloreto de Alumínio.

\section{EFFICIENCY OF COAGULANTS FOR MANGANESE REMOVAL}

Keywords: Water treatment, pollution, sanitary.

\begin{abstract}
The $\mathrm{Mn}$, if consumed in high concentrations by the population, can cause various health problems, especially if consumed by ingestion of drinking water. Thus, the aim of this study was to evaluate the efficiency of Mn removal in the raw water with the addition of coagulants and $\mathrm{Mn}$ ion concentrations in raw water. So, different concentrations of manganese were used: from 0, 2, 4 and $6 \mathrm{mg} \mathrm{L}^{-1}$, and it was evaluated three different coagulants: Aluminum Sulfate, Tannin and Aluminium Polychloride for water treatment in the water treatment station. The results showed that Tannin and Aluminium Polychloride coagulant presented the best potential for $\mathrm{Mn}$ removal, with the highest efficiency presented for Tannin coagulant in the raw water without adding $\mathrm{Mn}$, and the raw water with the addition of $2 \mathrm{mg} \mathrm{L}^{-1}$ of $\mathrm{Mn}$. The Aluminium Polychloride coagulant had the highest efficiency only for the raw water with the addition of $6 \mathrm{mg} \mathrm{L}^{-1}$ of the $\mathrm{Mn}$. Aluminum sulfate showed the worst removal rates. So, the better coagulant was the Aluminium Polychloride if the Mn concentration is higher than $2 \mathrm{mg} \mathrm{L}^{-1}$ in the raw water of the treatment station under study.
\end{abstract}




\section{INTRODUÇÃO}

Os impactos ambientais decorrentes do crescimento populacional e desenvolvimento econômico, evidenciados nas últimas décadas, são os principais responsáveis pela queda da qualidade de água (FLECK et al., 2013). A poluição dos corpos hídricos causada pelo lançamento de esgotos domésticos, águas pluviais contaminadas, efluentes industriais e resíduos sólidos é considerada um dos maiores problemas da atualidade, tornando cada vez mais difícil e oneroso o tratamento de água para consumo humano (YU et al., 2015).

Os recursos hídricos são limitados e, portanto, o tratamento de água são as únicas alternativas viáveis para obtenção da água potável. Deste modo, há uma grande necessidade no desenvolvimento de sistemas adequados, tecnologias baratas e técnicas rápidas para o tratamento da água (GUPTA et al., 2012).

Os processos de tratamento de água à base de coagulantes tornaram-se bem estabelecidos por serem facilmente controlados, eficazes e bem compreendidos (KEELEY; JARVIS; JUDD, 2014). Enquanto várias tecnologias de tratamento de água têm se mostrado eficazes em laboratório, nenhum outro procedimento tem acompanhado o desempenho no tratamento de água em grande escala como os coagulantes.

No processo de coagulação-floculação, a fim de remover a matéria inorgânica e orgânica, as partículas apresentam-se em suspensão ou em sistemas coloidais facilitando a sua remoção (STEFANESCU et al., 2015). Entretanto, é necessário entender qual coagulante aplica-se melhor a condição de água a ser tratada. Três categorias principais de coagulantes e floculantes podem ser identificadas como os sais metálicos hidrolisados, sais metálicos pré-hidrolisados e os polímeros orgânicos sintéticos (CULEA et al., 2009).

$\mathrm{Na}$ água bruta podem estar presentes diferentes elementos químicos. Nesse sentido, o manganês, quando presente em águas naturais de baixo $\mathrm{pH}$ e com ausência de oxigênio, apresenta-se sob a forma quimicamente reduzida sendo solúvel e incolor. Entretanto, quando é oxidado pela aeração ou pela aplicação de cloro, esse mineral é precipitado conferindo a água uma aparência púrpura à preto quando altas as suas concentraçóes (MORUZZI \& REALI, 2012).

Altas concentrações de manganês na água podem ocasionar diversos problemas para os consumidores que costumam reclamar sobre a coloração, sabor desagradável e odor. Entretanto, a exposição a altos níveis por inalação ou ingestão, podem causar efeitos adversos à saúde como a degeneração dos neurônios e dos movimentos abdominais (GUILARTE, 2011). Nos últimos anos, estudos têm sido conduzidos para avaliar a remoção de manganês por diferentes substâncias, procedimentos e microrganismos (BUTTERFIELD et al., 2013). Na regiáo de Pelotas, RS, há uma necessidade de se reduzir a concentração de metais e a redução do custo com coagulantes alternativos e ou eficientes é de fundamental importância para a região. Assim, o presente estudo visa analisar a eficiência de três coagulantes na remoção de Manganês em diferentes concentrações na água bruta da Estação de Tratamento de Água (ETA) da EMBRAPA Clima Temperado.

\section{MATERIAL E MÉTODOS}

O estudo foi conduzido na Estação de Tratamento de Água Terras Baixas, localizada no município do

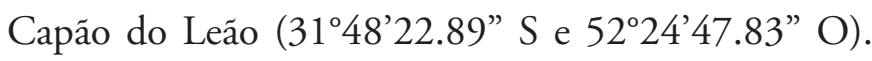
As análises físico-químicas da água realizadas foram turbidez, $\mathrm{pH}$, condutividade e as concentraçóes de Manganês após os diferentes tratamentos.

A metodologia Standart Methods for Examination of Water and Wastewater (EATON et al., 2005) foi utilizada para comparar o efeito dos três coagulantes testados pelo Teste de Jarros. A mistura rápida foi simulada na adição dos diferentes coagulantes na água por $1 \mathrm{~min}$, com uma rotação de $250 \mathrm{rpm}$. A mistura lenta foi simulada a uma velocidade de 40 rpm durante $12 \mathrm{~min}$, não gerando assim a quebra dos flocos que foram formados. $\mathrm{Na}$ decantação, a fase de sedimentação dos flocos, as paletas ficaram estáticas e o tempo de espera foi de $12 \mathrm{~min}$, de modo a permitir a decantação dos flocos e a clarificação. Em seguida, ocorreu a filtração e então foram retirados $300 \mathrm{~mL}$ de amostra para as análises.

Para as análises, foram utilizadas água bruta para os três tipos de coagulantes e então realizado os testes sem 
adição de Mn foram testadas e tratadas como controle. Além disso, os dados das simulaçóes só foram utilizados caso os três coagulantes atingissem uma turbidez igual ou inferior a 0,02 NTU, para simular uma coagulação eficiente.

As análises foram conduzidas em três etapas, sendo a primeira etapa constituída de 15 análises, sendo cinco repetições para cada coagulante, a fim de traçar um perfil comparativo das eficiências na remoção do Manganês na água bruta. $\mathrm{Na}$ segunda etapa o experimento foi conduzido com a adição de $2 \mathrm{mg}$ $\mathrm{L}^{-1}$ de Manganês na água bruta, através de uma solução padrão a $4 \% \mathrm{Mn}$, em cada Jarro com água bruta e a partir disso foi feito o Teste de Jarros e então realizada as 5 análises em triplicata. Os mesmos parâmetros da primeira fase foram utilizados nessa etapa. Por fim, na terceira etapa, a análise laboratorial anteriormente descrita foi realizada nas amostras com adição de $6 \mathrm{mg}$ $\mathrm{L}^{-1}$ de Manganês em cada jarro contendo água bruta. Também se seguiu os mesmos parâmetros das fases anteriores.

Em laboratório foi estabelecido um delineamento experimental inteiramente casualizado em arranjo fatorial $(3 \times 3)$, sendo três doses de manganês na água bruta (zero: teor natural, 2 e $6 \mathrm{mg} \mathrm{L}^{-1}$ de $\mathrm{Mn}$ ), três tipos de coagulantes (tanino, PAC e sulfato de alumínio), com 3 repetiçóes.

Os parâmetros de qualidade de água analisados foram condutividade elétrica, $\mathrm{pH}$, temperatura, turbidez e concentração total de Manganês. A condutividade elétrica foi medida no aparelho Conductivity Meter modelo CD-4301, o pH e a temperatura foram medidas no $\mathrm{pH}$-metro GRQ018 e a turbidez foi realizada com auxílio de um Turbidímetro AP2000 fabricado pela Policontrol. As análises da concentração total de Manganês foram mensuradas através do Fotocolorímetro ALFAKIT modelo AT100P empregando o método analítico da Formaldoxima para o comprimento de onda de $450 \mathrm{~nm}$.

\section{RESULTADOS E DISCUSSÃO}

Os resultados evidenciaram após a adição dos diferentes coagulantes valores de turbidez de 0,02
NTU para ambos os produtos utilizados e o $\mathrm{pH}$ manteve-se entre 6,1 e 6,2 (Tabela 1). No que se refere à qualidade da água tratada,os resultados dos parâmetros descritos foram superiores a Resolução 2.914/11 (BRASIL, 2011) (Tabela 1). Estes resultados demonstram que para este parâmetro os coagulantes foram eficientes na redução da turbidez, a água bruta e também não reduziram o $\mathrm{pH}$ a níveis que necessitem outros tratamentos complementares.

O coagulante Sulfato de Alumínio proporcionou a maior condutividade elétrica quando comparado aos outros coagulantes (Tabela 1). Isto ocorre devido a adição do íon alumínio, pois está relacionado à presença de alumínio residual na água após o tratamento (SILES et al., 2013).

Tabela 1. Valor médio encontrado nas análises de turbidez, $\mathrm{pH}$ e condutividade elétrica da água bruta (AB) e após o tratamento utilizando sulfato de alumínio (SA), Policloreto de Alumínio (PAC) e Tanino vegetal (TA).

\begin{tabular}{cccc}
\hline Tratamentos & $\begin{array}{c}\text { Turbidez } \\
\text { (NUT) }\end{array}$ & pH & C.E.(s/m) \\
\hline AB & $13,82 \pm 2,27^{*}$ & $6,3 \pm 0,10$ & $99,24 \pm 14,01$ \\
SA & $0,02 \pm 0,03$ & $6,1 \pm 0,18$ & $167,72 \pm 48,31$ \\
PAC & $0,02 \pm 0,03$ & $6,2 \pm 0,16$ & $158,32 \pm 18,97$ \\
TA & $0,02 \pm 0,03$ & $6,1 \pm 0,13$ & $122,67 \pm 10,93$ \\
\hline Permitido CONAMA & 5,0 & 6,0 a 9,0 & - \\
\hline
\end{tabular}

*Valores significam média de 3 repetições \pm desvio padrão.

De acordo com os resultados obtidos na Tabela 1 , no que diz respeito à turbidez, pode-se perceber que a água bruta $(\mathrm{AB})$ com valor de turbidez de 13,82 NUT, segundo a legislação do CONAMA (2005), seria classificada como Classe 1. Entretanto, a turbidez da água bruta sofre mudanças ao longo do ano, devido às variaçóes climáticas da região podendo aumentar em condiçôes de seca e de fortes chuvas.

A remoção de manganês da água bruta e com adiçôes de 2 e $6 \mathrm{mg} \mathrm{L}^{-1}$ de manganês evidenciou o alto potencial de remoção de manganês da água bruta da região (Figura 1). Com este estudo, foi possível observar uma alta eficiência dos três coagulantes utilizados no experimento para a remoção de $\mathrm{Mn}$ da água. Essa baixa eficiência também foi encontrada por Prianti et al. (2005) comparando os coagulantes: Policloreto de Alumínio, Sulfato de Alumínio e Cloreto Férrico. 
Após análise das amostras utilizadas com os diferentes coagulantes é possível notar que, embora haja uma maior eficiência do PAC (com adição de 6 $\mathrm{mg} \mathrm{L}^{-1}$ de $\mathrm{Mn}$ ) e do Tanino (com adição de $2 \mathrm{mg} \mathrm{L}^{-1}$ de $\mathrm{Mn}$ ), há uma tendência parecida de remoção com um alto R2 (acima de 0,9) (Figura 2). Em outras palavras, em virtude da remoção de manganês os coagulantes não diferem profundamente entre si, pois as porcentagens de remoção são baixas quando comparada com o valor máximo permitido em Lei, remanescente a Portaria No 2914/11 (BRASIL, 2011) o qual o limite é $0,1 \mathrm{mg} \mathrm{L}^{-1}$.

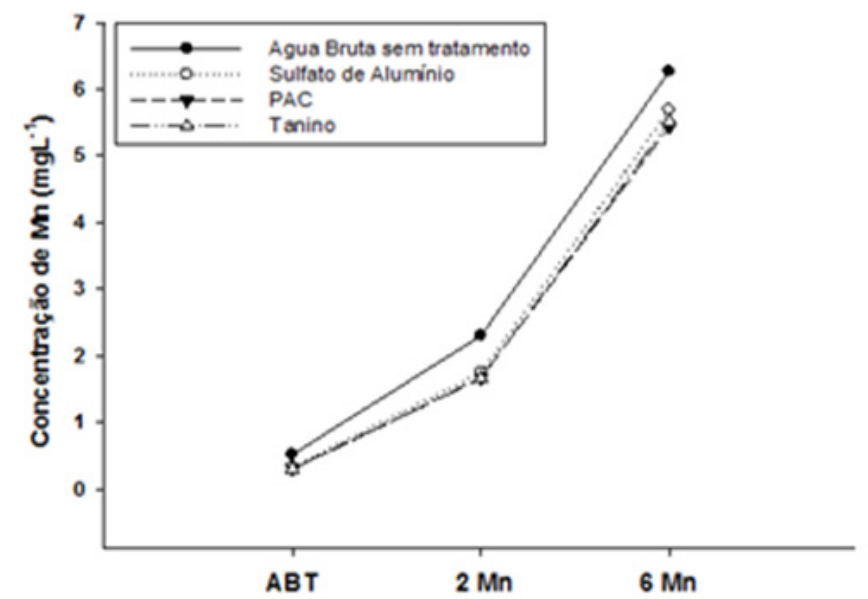

Figura 1. Análise de remoção de manganês(Mn) após o processo de floculação com os coagulantes sulfato de alumínio, tanino e Policloreto de Alumínio (PAC) naágua bruta tratada (ABT),com adição de 2 (2 Mn) e 6 (6 Mn) mg $\mathrm{L}^{-1}$ de manganês.

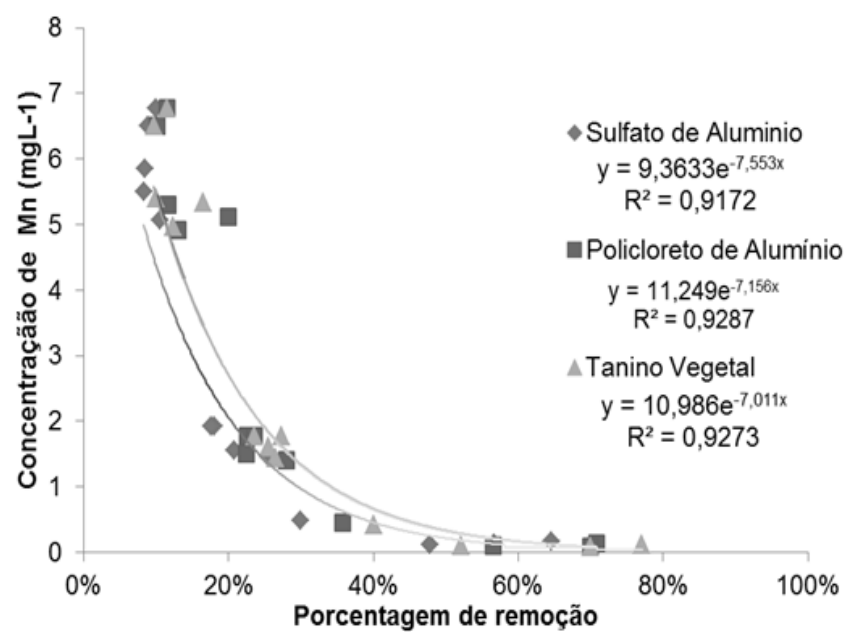

Figura 2. Relação da concentração $\left(m g L^{-1}\right)$ com a eficiência em porcentagem de remoção de $\mathrm{Mn}$.

O percentual de remoção de manganês, para a água bruta com uma concentração média de $\mathrm{Mn}$ em $0,52 \mathrm{mg} \mathrm{L}^{-1}$, demonstra que o coagulante Tanino possibilitou maior remoção seguido do coagulante PAC, com a adição de $2 \mathrm{mg} \mathrm{L}^{-1}$ de $\mathrm{Mn}$ percebeu-se que o PAC e o Tanino apresentam resultados similares de remoção, e na água bruta com adição de $6 \mathrm{mg} \mathrm{L}^{-1}$ observa-se que o PAC possibilita maior remoção(Tabela 2).Desse modo, os coagulantes Tanino e Policloreto de Alumínio demonstraram maior remoção de manganês tanto na água bruta tratada sem adição quanto nas águas com adição de 2 e $6 \mathrm{mg} \mathrm{L}^{-1}$ de manganês usando a solução padrão. É importante ressaltar que quanto mais elevada à concentraçáo de manganês na água bruta menor é a eficiência de remoção de manganês, para os três coagulantes utilizados, para a concentração de coagulantes utilizadas neste trabalho. Dessa forma, faz-se necessário o desenvolvimento de estudos para determinar a concentração adequada de coagulantes de acordo com as condiçóes químicas da água bruta.

Tabela 2. Porcentagem de remoção de manganês da água bruta tratada (ABT), com adição de 2 (2 Mn) e 6 ( 6 $\mathrm{Mn}) \mathrm{mg} \mathrm{L}^{-1}$ de manganês após a adição dos diferentes coagulantes: Sulfato de Alumínio, Policloreto de Alumínio e Tanino.

\begin{tabular}{lccc}
\hline & $\begin{array}{l}\text { Sulfato de Alumínio } \\
(\%)\end{array}$ & $\begin{array}{l}\text { Policloreto de Alumínio } \\
(\%)\end{array}$ & $\begin{array}{l}\text { Tanino } \\
(\%)\end{array}$ \\
\hline ABT & 46,92 & 53,08 & 54,23 \\
$2 \mathrm{Mn}$ & 24,00 & 27,43 & 27,91 \\
$6 \mathrm{Mn}$ & 9,25 & 13,27 & 12,03 \\
\hline
\end{tabular}

Em experimentos utilizando o coagulante orgânico de Moringa Oleifera realizados por Mendes et al. (2007) aplicado para amostras de água de torneira com a concentração de manganês de $2,0 \mathrm{mg} \mathrm{L}^{-1} \mathrm{e}$ $5,0 \mathrm{mg} \mathrm{L} \mathrm{L}^{-1}$, observou-se uma reduçáo de 50,9\% e $39,6 \%$ de manganês, respectivamente com $50 \mathrm{mg}$ de massa de moringa, uma vez que cada coagulante tem uma determinada capacidade de adsorção do metal.

Entretanto um estudo conduzido por Moruzzie Reali (2004), demonstrou que a remoção do manganês utilizando o Cloreto Férrico $\left(\mathrm{FeCl}_{3^{-}} 6 \mathrm{H}_{2} 0\right)$ apresentou eficiência superior a $36 \%$ e este resultado foi obtido através das funçôes de variaçóes de $\mathrm{pH}$ e de variações de dosagens do coagulante, sendo o seu melhor resultado quando utilizado a dosagem de Cloreto Férrico à $30 \mathrm{mg} \mathrm{L}^{-1}$ no valor de $\mathrm{pH}$ de 5,85 obtendo uma eficiência de remoção do manganês de 64\%. 


\section{CONCLUSÃO}

Os resultados de remoção de $\mathrm{Mn}$ da água bruta daEstação de Tratamento de Água (ETA) da EMBRAPA Clima Temperadodemonstraram-se positivos para a remoção dos íons de manganês, entretanto os valores ainda apresentavam-se elevados para a potabilidade.

O coagulante a base de Tanino de origem Vegetal apresentou maior eficiência de remoção de $\mathrm{Mn}$ equivalente ao Policloreto de Alumínio e superior ao sulfatode alumínio.O presente estudo apresentase como uma ferramenta de auxílio para a escolha do coagulante com melhores índices de eficiência de tratamento para as características apresentadas pela água bruta. Desta forma, manter a qualidade da água adequada e dentro dos padróes estabelecidos para consumo, é de fundamental importância para a sociedade e a saúde da populaçáo.

\section{LITERATURA CITADA}

BUTTERFIELD, C.N.; SOLDATOVA, A.V.; LEE, S.W.; SPIRO, T.G.; TEBO, B.M. Mn (II, III) oxidation and $\mathrm{MnO} 2$ mineralization by an expressed bacterial multicopper oxidase. Proceedings of the National Academy of Sciences, v.110, n.29, p.11731-11735, 2013.

BRASIL. Resolução CONAMA 357, de 17 de março de 2005. Conselho Nacional de Meio Ambiente. In: Diário Oficial da União no 053 , de 18 de março de 2005. Disponível em <http:// www.mma.gov.br/port/conama/legiabre.cfm?codlegi=459>.

BRASIL. Portaria MS No 2914,de12 de dezembro de 2011. Ministério da Saúde. In: Diário Oficial da União, 12 de dezembro de 2011. Disponível em <http://www.saude.mg.gov.br/index. php?option=com_gmg\&controller $=$ document $\& i d=8014$.

CULEA, M., IORDACHE, A.; COZAR, O.; RISTOIU, D. Trihalomethanes analysis in drinking water. Journal of Environmental Protection and Ecology, v. 10, n. 2, p. 342-350, 2009.

EATON, A. D.; CLESCERI, L. S.; RICE, E. W.; GREENBERG, A. E.; FRANSON, M. A. H. (Ed.). Standard methods for the examination of water and wastewater. 21. ed. Washington, D.C.: American Public Health Association, 2005.

FLECK, L.; TAVARES, M.H.F.; EYNG, E. Especificidades e importância de modelos matemáticos de qualidade da água. Revista Eixo v. 2, n. 1, p. 1062013.

GUILARTE, T.R. Manganese and Parkinson's disease: a critical review and new findings. Ciencia \& saudecoletiva, v. 16, n. 11, p. 4519-4566, 2011.

GUPTA, V.K.; ALI, I.; SALEH, T.A.; NAYAK, A.; AGARWAL, S. Chemical treatment technologies for waste-water recyclingan overview. RSC Advances, v. 2, n. 16, p. 6380-6388, 2012. KEELEY, J.; JARVIS, P.; JUDD, S.J. Coagulant recovery from water treatment residuals: a review of applicable technologies. Critical reviews in environmental science and technology, v. 44, n. 24, p. 2675-2719, 2014.
MENDES, F.M. Estudo do uso da Moringa oleifera para remoção de prata e manganês em águas. Horizonte Científico, v. 1, n. 1, 2007.

MORUZZI, R.B.; REALI, M.A.P. Oxidação e remoção de ferro e manganês em águas para fins de abastecimento público ou industrial-uma abordagem geral. Revista de Engenharia e Tecnologia, v. 4, n. 1, p. Páginas 29-43, 2012.

STEFANESCU, M.;COSMA, C.; CRISTEA, I.; NITOI, I.; BUMBAC,C.; BADESCU, V. Drinking water treatment with recovered flocculant from alumina fabrication process. Journal of Environmental Protection and Ecology, v. 16, n. 4, p. 1509$1514,2015$.

YU, W.;CAMPOS, L.; SHI, T.; LI, G.; GRAHAM,N. Enhanced removal of manganese in organic-rich surface water by combined sodium hypochlorite and potassium permanganate during drinking water treatment. RSC Advances, v. 5, n. 35, p. $27970-$ 27977, 2015 